\title{
Hedging Customer Risk
}

\author{
Christopher Groening • Pinar Yildirim • Vikas Mittal • \\ Pandu Tadikamalla
}

Published online: 3 April 2014

(C) Springer Science+Business Media New York 2014

\begin{abstract}
Companies and academics rarely account for balancing the risk and reward in a customer portfolio of a firm. Unlike a stock portfolio where both measures are taken into account, many people tend to look only at the customers' average profit value. Applying financial portfolio management techniques to customer management has been an under-researched topic in academic marketing literature. In this paper, we propose a methodology that allows firms to create a customer portfolio maximizing return for a level of risk. We illustrate the potential benefits by optimally weighting the customer segments based on their risk-reward impact on the firm's overall customer portfolio. Our method can be used to assist investors in their valuation of a firm or to value an acquisition with a primary goal of increasing the customer base. We use a dataset of 1,901 customers covering seven quarters for a total of 13,307 observations of a major US bank with a market capitalization exceeding $\$ 40$ billion. We show measurable potential increase in profit by implementing customer portfolio management practices.
\end{abstract}

\author{
C. Groening \\ Kent State University, 522 Business Administration Building, Kent, \\ OH 44242, USA \\ e-mail: cgroenin@kent.edu \\ P. Yildirim $(\bowtie)$ \\ University of Pennsylvania, 748 Jon M. Huntsman Hall, 3730 \\ Walnut Street, Philadelphia, PA 19104-6304, USA \\ e-mail: pyild@wharton.upenn.edu \\ V. Mittal \\ Jones Graduate School of Business, Rice University College of \\ Medicine, 250 McNair Hall, Houston, TX 77005, USA \\ e-mail: vmittal@rice.edu \\ P. Tadikamalla \\ Katz Graduate School of Business at the University of Pittsburgh, \\ 258 Mervis Hall, Pittsburgh, PA 15260, USA \\ e-mail:pandu@katz.pitt.edu
}

Keywords Customer portfolio $\cdot$ Embeddedness $\cdot$ Portfolio optimization · Risk

"Risk management will come to define the events of
2008 and after."
Goldman Sachs Group's Chief Executive Lloyd
Blankfein [1]

\section{Introduction}

Risk is an integral component of a firm's financial health, value, and sustainability $[2,3]$. Yet, when addressing their most valuable asset, customers, firms may neglect consideration of the risk associated with them. The financial investors are aware of the risk and reward inherent in different assets and therefore create portfolios of assets by continually balancing these two factors. Firms attempt to manage volatility through diversification of business segments $[4,5]$. Similarly, marketing managers can recognize that customers need to be managed for risk and return. "In fact, strategic adaptation by skillful, rigorous, and continuous management of unsystematic risk lies at the heart of strategic management" [6 p. 408].

This paper examines the concerns and benefits of a portfolio-selection approach for helping a firm to create an optimal portfolio of customer segments for a targeted risk level. Our proposed methodology has roots in portfoliomanagement theory, which incorporates the risk and return inherent in different assets. Although a portfolio of assets and a portfolio of customers both strive to measure and account for risk and return, there are differences between the two [7, 8]. These differences are described in Table 1. 
Table 1 Comparison of portfolio of stocks and customer segments

\begin{tabular}{|c|c|c|}
\hline Issue & Return on stocks & Return on customer segments \\
\hline Correlation & $\begin{array}{l}\text { Risk reduction stems from whether segments } \\
\text { have weakly correlated or negatively } \\
\text { correlated returns }\end{array}$ & $\begin{array}{l}\text { Firms should diversify in order to create } \\
\text { segments that have weakly correlated } \\
\text { or negatively correlated returns }\end{array}$ \\
\hline Size of portfolio & $\begin{array}{l}\text { Diversifying a firm's stock portfolio may } \\
\text { help to reduce risk }\end{array}$ & $\begin{array}{l}\text { There is a limit to the number of segments } \\
\text { that a firm may be able to manage }\end{array}$ \\
\hline Size of individual holding & Holdings may be of any size & $\begin{array}{l}\text { Segment size must be of a certain size to } \\
\text { devote resources to its maintenance }\end{array}$ \\
\hline $\begin{array}{l}\text { Stability of Segment size } \\
\quad \text { (outside of portfolio holders control) }\end{array}$ & $\begin{array}{l}\text { The amount of stocks for a given firm will only } \\
\text { change due to stock splits, but value will } \\
\text { stay the same }\end{array}$ & $\begin{array}{l}\text { Customers, due to their changing characteristics } \\
\text { or own volition, may enter or leave segments }\end{array}$ \\
\hline $\begin{array}{l}\text { Advanced financial instruments } \\
\text { (e.g., borrowing, shorting, options) }\end{array}$ & $\begin{array}{l}\text { Stocks may be subject to a number of financial } \\
\text { instruments }\end{array}$ & $\begin{array}{l}\text { The same advanced financial instruments } \\
\text { are not feasible to adopt in a customer } \\
\text { portfolio setting }\end{array}$ \\
\hline Objective & $\begin{array}{l}\text { Maximize return and minimize risk in } \\
\text { monetary terms }\end{array}$ & $\begin{array}{l}\text { There may be other objectives in addition to } \\
\text { monetary considerations such as economies } \\
\text { of size and scale }\end{array}$ \\
\hline Interconnectedness & Investor actions rarely can affect stocks & Firm actions usually have an effect on customers \\
\hline
\end{tabular}

We provide a roadmap for managers to achieve the optimal customer portfolio (please see Fig. 1). Our roadmap can help managers to determine an acceptable level of risk and return for the customer portfolio, the number of customer segments to be managed, and the ideal weight (i.e., proportion of customers) for each segment. Our prescription for developing the optimal customer portfolio includes methods for incorporating customer acquisition and divestment costs. Please note that the goal of our paper is not to develop a segmentation methodology or to develop new methodologies for measuring customer lifetime value (CLV). Moreover, our methodology does not provide guidance into selecting among different segmentation schemes. ${ }^{1}$ Rather, it aims to provide guidance on incorporating both risk and return into existing segmentation methods that a firm already has established. This approach, therefore, may work well for firms with stable institutional environments where the goal is to optimize existing customer segments, rather than design new segmentation schemes.

This study contributes to customer management literature in a number of ways. First, it provides a model that enables firms to evaluate their portfolio of customer segments focusing on an overall level of risk and return. Second, it extends work by previous scholars $[9,3,10]$ by detailing a systematic method that enables a firm to determine the optimal number of customers per segment along with incorporating differing acquisition, maintenance and divestment costs. Third, we show practitioners how to adapt our methodology to their firm's specific needs [11]. Fourth, we address concerns that accompany applying stock portfolio theory to customer assets.

\footnotetext{
${ }^{1}$ Some of these segmentation schemes used by marketers may be psychographics, demographics, and CLV-based segmentation.
}

Overall, our goal is to demonstrate the ease and effectiveness of incorporating customer risk into customer management.

\section{Roadmap for Obtaining an Optimal Customer Portfolio}

\begin{tabular}{|c|}
\hline $\begin{array}{c}\text { Step 1: Segment customers } \\
\text { Use firm specific method } \\
\text { (Our example used Equations 9-10) }\end{array}$ \\
\hline
\end{tabular}

Step 2: Analyze current customer segment

Estimate the return and risk level of each customer segment, and correlation between segments (Equations 2-5)

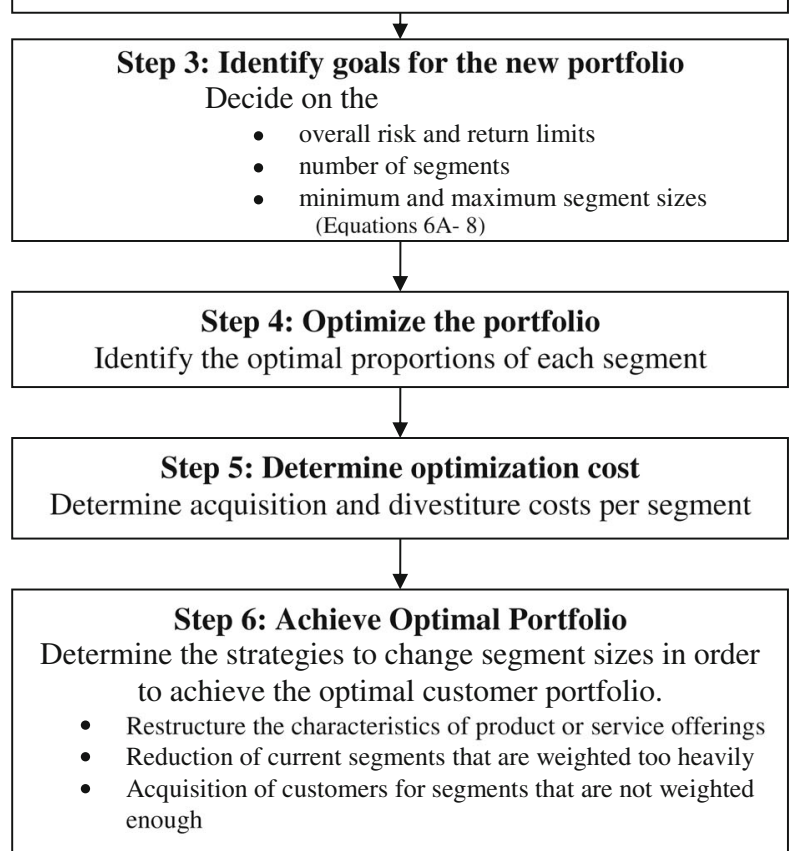

Fig. 1 Roadmap for obtaining an optimal customer portfolio 
We illustrate our methodology using a real world, longitudinal dataset of seven quarterly observations for 1,901 individual customers from a large bank in the Midwest.

\section{Literature Review}

\subsection{Portfolio Theory}

In a traditional view of an investment portfolio, a group of individual stocks may be classified together, for instance by sector (e.g., finance, biotechnology, and consumer goods). Investors then balance the risk and returns of these classifications to meet their specific goals. Some goals, such as capital maintenance, may be more conservative, taking on minimal risk. More risky goals, such as trying to maximize a retirement portfolio, may risk short-term losses for greater long-term gains. A firm may think of each customer as analogous to an individual stock, and a customer segment as equivalent to a sector. Thus, the firm must balance the risk and return levels of each of their customer segments in order to achieve their financial goals.

Portfolio theory allocates assets to achieve an optimal trade-off between return (mean) and risk (variance) over a given time horizon [12]. For stocks, return is defined as the cash flow to the investor plus the change in market value, while risk is defined as the variance of the returns [13]. While customer return corresponds to the profit generated from that customer, Ryals [14] suggests that there are two ways to interpret customer risk: (a) risk of customer switching, i.e., the probability that customer defects, and (b) the variance in the revenue stream obtained from the customer. In this study, we employ the latter view to define customer risk $[15,16]$.

Typically, to obtain a higher expected return from a portfolio, the decision maker must take on a higher level of risk. A portfolio constructed of multiple assets rather than a single asset frequently results in a less risky investment with the same level of expected return because it incorporates the covariance in the different asset returns [17]. The curve produced by the boundary of the points representing all portfolios is referred to as the efficient frontier; that is, the maximum possible return for each level of risk [17].

\subsection{Portfolio Theory and Management of Customer Segments}

A company's customer base may be segmented using factors such as geography [e.g., [18, 19], product line [e.g., 20, 21], or the type of relationship between the customer and firm [e.g., $22,23]$. For instance, in financial services, customers may be segmented into retail versus business segments [e.g., 24]. Other approaches include transactional and behavioral customer data such as purchase type, volume, history, call center complaints, claims, and web activity to segment the customer base [25-27]. Other methods look at potential benefit [28], customer defection probability [29], and customer lifetime value (CLV) [30, 31]. Most established businesses have an existing segmentation methodology and are interested in understanding how existing segments can be used to achieve the highest return value. Each customer segment is maintained through specific levels of resources spent on activities such as advertising, sales, and maintenance. Using insights from portfolio management theory, the amount of customers in each segment can be optimized to achieve the desired risk-reward levels.

The concept of applying portfolio management theory outside of the financial investment arena is not new. It has been used in areas such as buyer-seller relationships [e.g., 32], industry segments [e.g., 33] and products [34-36]. Within the customer management literature, Dhar and Glazer [9] were among the first to provide a case example. Although they did not provide quantitative details regarding how the industrial firm balanced its customer portfolio, their work laid the foundation for examining customers as a collection of assets, rather than just as a profit stream. Gupta, Lehmann, and Stuart [3] present work determining the value of a customer to the firm. Other authors incorporate the trade-offs between scale economies and lifetime customer value [37], and segment switching [38]. Similarly, Tarasi et al. [10] incorporate the mean as well as the variance of customer segment cash flows, along with the covariance among the segment cash flows. We build on this prior work and in addition, we examine the impact of differential customer acquisition and divestment costs.

Before embarking on the steps to create an ideal customer portfolio we need to differentiate more precisely between a portfolio of stocks and one of customer segments [7]. First, the ideal portfolios of either type need to exhibit negative correlation between the payoffs of their constituent parts to diversify away risk. Second, while a stock portfolio usually can diversify away risk with a portfolio of 20-30 different firms, the ability to manage the number of customer segments may be beyond the capabilities of a firm. However, as we illustrate later, there are diminishing returns as the number of customer segments increases, so the ability to create and manage a large number of customer segments may not be a major concern. Third, the costs in maintaining differing numbers of stocks in each portfolio segment may not vary that greatly, but there may be a threshold for the minimum number of customers in a customer segment due to associated costs. Fourth, customers may discontinue transactions with a firm, while non-sentient stocks are unable to pursue such recourse. Fifth, while creating an optimal portfolio of stocks, an investor may use various financial instruments, such as short selling or using leverage to obtain an optimal portfolio. There is no equivalent while creating an optimal customer segment portfolio; one cannot borrow customers in hopes that their value goes down as an investor may do when short selling stocks. Sixth, the main 
goal in a financial portfolio usually is to maximize return, while minimizing risk. However, customer management may need to develop certain segments of customers that do not match this specific goal. Finally, it is not often that individual investors are able to directly affect the performance of stocks, yet a firm's actions often have direct consequences on the cash flow from existing customers.

Figure 1 summarizes the steps that should be taken to obtain the optimal customer portfolio. A firm should begin by segmenting customers utilizing the method most suitable to the firm's circumstances. For example, a bank may use the number and size of bank accounts per customer. Our approach assists in providing the optimal customer allocation for a firm's given segmentation method, rather than imposing one. The next step is to determine the level of risk and average return for each segment, as well as the correlation of returns between segments. This step is critical for optimal balancing of the customer portfolio. In the third step, firms determine overall goals, such as maximum risk level, desired return level, and feasible number and size of segments to manage. These decisions are then used as inputs in the fourth step where an optimal portfolio is obtained. Step five can be conflated with step four. Rebalancing the customer portfolio is not a cost-free endeavor. There are costs associated both with acquiring and divesting customers that need to be calculated for each segment. These costs can play a significant role in determining the optimal customer portfolio position. Finally, step six is where a firm needs to decide how to move from their current portfolio to the portfolio suggested by the optimization procedures in the previous steps.

\subsection{Customer Costs}

To reach the optimal portfolio structure, a firm typically incurs three types of costs: customer acquisition, retention, and divestment costs.

Acquisition Costs Acquisition costs are related to acquiring new customers and may take the form of advertising, providing incentives, sales efforts, or obtaining customers through purchase of an existing firm [30, 39].

Retention Costs Costs relating to management of current customers can be categorized as either operational or for retention. These expenditures may be incurred to increase customer retention and profitability, and include production, delivery, inventory, configuration, and customer relationship management (CRM) [29].

Divestment Costs Divestment costs relate to the costs incurred in order to cut or reduce the relations with a customer [40, 41].

\subsection{Risk-Reward Measurement}

Although a number of ways to quantify the risk-reward ratio of a portfolio are available, the metric used most often is the Sharpe ratio $(S)$ which combines two measurements, the mean and standard deviation of a portfolio, into one metric [42-45].

The Sharpe ratio is defined as:

$S=\left(R_{F}-R_{B}\right) / \sigma$

where $\sigma$ is the standard deviation of the portfolio, $R_{F}$ is the average rate of return of portfolio, and $R_{B}$ is the return of a benchmark security. We will adopt a similar measure to compare risk and return.

\subsection{Segment Size}

The size of customer segments is a managerial concern. A segment with a large percentage of the firm's total number of customers may produce less diversification and present a high risk. Similarly, a firm may need a minimum number of customers in a segment to maintain adequate infrastructure to service that particular segment. We consider this trade-off in calculating ideal number of customers for a specific segment.

\section{Model}

Assume a firm has $N$ customer segments where segment $i$ has $n_{i}$ customers. The total number of customers $(T N)$ is thus defined as the sum of the customers in each segment.

$\mathrm{TN}=\sum_{i}^{N} n_{i}$

In order to have comparable dollar values, Eq. 3 adjusts all revenue values $\widetilde{P}_{j i t}$ of customer $j$, in segment $i$, at time $t$, to present day values using a discount rate of $d$ :

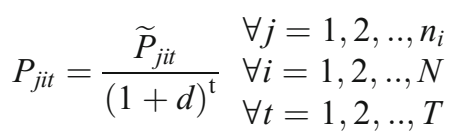

Equations $4 \mathrm{~A}$ and $4 \mathrm{~B}$ calculate the average return, or profit $\bar{P}$, for each segment $i$. The result will be used to calculate both the risk and return of the entire portfolio.

$P_{i t}=\sum_{j=1}^{n_{i}} \mathrm{P}_{\mathrm{jit}} \quad \begin{aligned} \forall i & =1,2, . ., N \\ \forall t & =1,2, . ., T\end{aligned}$

$\overline{P_{i}}=\frac{1}{T} \sum_{t=1}^{T} \mathrm{P}_{\mathrm{it}} \forall i=1,2, . ., N$ 
The covariance calculated in Eq. 5 will be used to calculate the risk level of the entire portfolio. Covariance needs to be calculated between all pairs of segments.

$\operatorname{Cov}\left(P_{i}, P_{k}\right)=\frac{1}{T-1} \sum_{t=1}^{T}\left(\left(P_{i t}-\overline{P_{i}}\right)\left(P_{k t}-\overline{P_{k}}\right)\right) \begin{aligned} & \forall i=1,2, \ldots, N \\ & \forall k=1,2, \ldots, N\end{aligned}$

The attractiveness of any customer segment is evaluated depending on the mean profit score and its variance. Higher average return and lower variance result in a more attractive segment. Once the present value of the cash flow from a customer is calculated, the classical Markowitz portfolio model [46] can be used to select the portfolio through two methods. One, the portfolio may be chosen using a preferred level of risk as defined by the standard deviation of the portfolio return $\left(\sigma_{\text {targeted }}\right)$. Two, the portfolio may be chosen using return as defined by the mean of the portfolio return ( $\left.\mu_{\text {targeted }}\right)$. Obviously, neither method of selecting a portfolio, by risk or reward, is superior to the other; the appropriateness of the method depends on management's risk tolerance. Feasible solutions from the Markowitz models given above will result in portfolios with a given percentage of the customer base assigned to each customer segment. For instance, an ideal portfolio may consists of $25 \%$ of the customer base with the risk-reward characteristics of segment one, $30 \%$ of customers with the risk-reward characteristics of segment two, and $45 \%$ the risk-reward characteristics of segment three. Empirically, the percentage of each selected customer segment must be a non-negative value and the sum of all percentages will equal $100 \%$. We introduce the following two portfolios that a firm may utilize:

Portfolio A: Minimize customer risk such that customer portfolio return is greater than or equal to $\mu_{\text {targeted: }}$ :

$$
\operatorname{Min}_{\left\{\theta_{i}\right\}_{i=1}^{N}} \sqrt{\sum_{i=1}^{N} \sum_{k=1}^{N} \theta_{i} \theta_{k} \operatorname{Cov}\left(P_{i}, P_{k}\right)}
$$

$$
\text { s.t. } \sum_{i=1}^{N}\left[\theta_{i} \overline{P_{i}}\right] \geq \mu_{\text {targeted }}
$$

Portfolio B: Maximize customer return such that customer portfolio risk is less than or equal to $\sigma_{\text {targeted: }}$ :

$$
\begin{aligned}
& \underset{\left\{\theta_{i}\right\}_{i=1}^{N}}{\operatorname{Max}} \sum_{i=1}^{N}\left[\theta_{i} \overline{P_{i}}\right] \\
& \text { s.t. } \sqrt{\sum_{i=1}^{N} \sum_{k=1}^{N} \theta_{i} \theta_{k} \operatorname{Cov}\left(P_{i}, P_{k}\right)} \leq \sigma_{\text {targeted }}
\end{aligned}
$$

where $\theta_{i}$ is the proportion of customers allocated to segment $i, N$ is the number of segments, and $\sum_{\mathrm{i}} \theta \mathrm{i}=1, \theta_{i} \geq 0, \forall \mathrm{i}=1,2, \ldots, N$

The above eq. (6A-7B) dictate the proportion of customer in each segment, yet a firm may have reasons for constraining the outcomes of these equations. They may wish to maintain the proportion of customers in a specific customer segment above a certain level for several reasons. First, it may be infeasible for firms to cater to a very small number of customers in each segment [47]. Second, due to regulatory and non-marketing reasons, a firm may be unable to eliminate an entire group of customers. Finally, a firm may not want to lose its presence in specific segments for competitive reasons and not want to cede market share to rivals. For other reasons, the firm may wish to keep the proportion of customers below a certain level; to minimize risk, keep administrative costs at a certain level, or because the segment may be necessary but not profitable. However, it should be remembered that implementing such constraints may lead to a suboptimal solution. These lower and upper bound constraints are given next in Eq. 8,

$L_{i} \leq \theta_{i} \leq U_{i}, \forall i=1,2, \ldots, N$

where $L_{i}$ is a constant that represents the minimum desired proportion and $U_{i}$ is a constant that represents the maximum desired proportion for customer segment $i$.

Given the above model specification, Portfolio A (minimized risk) represents customer segments that ensure the firm receives its target profit of $\mu_{\text {targeted }}$ with the lowest possible risk in the profit stream, and Portfolio B (maximized return) is the selection of customer segments that ensures the firm the highest return for a predetermined level of risk, $\sigma_{\text {targeted. }}$ It is important to note that our model assumes that there can be no borrowing of customers, unlike stocks. In other words, it is not possible to obtain a return from a customer segment without actually investing in it. Stated differently, a firm must receive returns from actual customers in its portfolio.

\section{Empirical Application}

\subsection{Data}

We use a customer dataset from a large bank headquartered in the Midwest with more than 800 branches, market capitalization of more than $\$ 40$ billion, and offers a full range of products. The bank defines a customer as a household that conducts business with the bank. The dataset is composed of a random sample of 1,901 customers from the retail-banking sector covering seven quarters for a total of 13,307 observations. 
Each customer in the dataset had financial data, including profit margins, from three different accountsdeposits, loans, and investments. Table 2 describes the summary statistics of our sample, along with the three segments that were used for our example. The sample represents 647 branches. Branches where $95 \%$ of the customers have deposit accounts while $23 \%$ have loans, and $9 \%$ have investment accounts. On average each customer generated $\$ 90$ in pre-tax profit per year.

Segmentation The bank uses brand embeddedness scores to segment its retail customers. This concept is similar to relational commitment whereby trust, agreements, and investments result in higher satisfaction, long-term commitment and higher profits [48]. The concept of brand embeddedness captures the strength and breadth of the customer's relationship with a firm. For instance, the bank considers a customer with $\$ 100,000$ in deposits to have a higher embeddedness level with the bank than another customer with only $\$ 1,000$ in deposits. Additionally, the customer with a $\$ 50,000$ loan and $\$ 50,000$ in deposits is seen by the bank to have higher embeddedness than a customer with only $\$ 100,000$ in deposits, since the former customer has more than one mode of contact with the bank. From the perspective of the bank's management team, embeddedness lends itself elegantly to operationalizing a relationship-based approach to its customers. Theoretically, it is consistent with a multichannel segmentation approach that can lead to higher repeat purchases, customer longevity, and larger transactions [49].

In our study, embeddedness is based on three aspects of a relationship with the bank: loans, deposits, and investments held. The amount that each customer has in these three accounts is weighted equally and an overall embeddedness score is obtained. Equation 9 shows how to calculate the embeddedness score of each customer in each time period,

$E_{j t}=\sum_{i=1}^{\tau}\left(A B_{j t a}\right) a \in \tau=\{$ loans, deposits, investments $\}$

where $A B_{j t a}$ is the account balance for customer $j$ for period $t$ in account $a$.

Then order the customers in ascending order, from smallest to largest by embeddedness score, for each time period $t$ :

$E_{l t} \leq E_{2 t} \leq \ldots \leq E_{T N t} t=1,2, \ldots T$

Once the customers are ordered, they may be divided into segments based on embeddedness scores. For instance, values such as $[-3,-1,0,1,3]$ can be used as thresholds. The division of customers into segments need not produce an equal number of customers per segment and customers may move between segments over time. Moreover, the determination of the number of segments is firm specific. Table 3 shows the different means and standard deviations of pre-tax profit for different numbers of customer segments using the bank data. Segment 1 contains customers with the lowest embeddedness scores, while the highest numbered segment contains the ones with the highest embeddedness scores. Whereas some segments have a negative average return, for all segments zero return is within one standard deviation of the average return, which means that the return has a likelihood of being positive. Figure 2a(1) plots the data shown in Table 3 . Figure $2 \mathrm{a}(2)$ was created because so many segments are clustered around a mean of $\$ 15$ and a standard deviation of $\$ 95$. For example, the portfolio with eight segments is represented by eight $\Delta \mathrm{s}$. In Fig. $2 \mathrm{a}(1)$, only three of the $\Delta \mathrm{s}$ are discernible. The other five $\Delta$ s overlap in a cluster at the bottom

Table 2 Customer description

\begin{tabular}{llllll}
\hline & & Overall & Segment 1 & Segment 2 & Segment 3 \\
\hline Profit (\$) & Mean & 76.29 & 13.26 & 10.84 & 204.93 \\
& Std. Dev. & 136.15 & 61.51 & 56.93 & 208.64 \\
Embeddedness & Mean & 0.00 & -0.63 & -0.35 & 0.98 \\
& Std. Dev. & 1.18 & 0.22 & 0.06 & 1.63 \\
Number of branches & & 641 & 378 & 405 & 385 \\
Deposit accounts & Percent (\%) & 96.47 & 97.31 & 97.47 & 94.63 \\
& Mean (\$) & $16,962.11$ & $4,137.33$ & $5,463.71$ & $41,249.92$ \\
Loan accounts & Std. Dev. (\$) & $129,882.93$ & $15,697.98$ & $26,499.38$ & $177,036.87$ \\
& Percent (\%) & 26.68 & 34.76 & 10.74 & 34.60 \\
Investment accounts & Mean (\$) & $28,758.17$ & $5,500.63$ & $15,252.29$ & $61,016.59$ \\
& Std. Dev. (\$) & $127,576.35$ & $15,186.14$ & $25,886.15$ & $173,568.26$ \\
& Percent (\%) & 9.32 & 6.79 & 6.00 & 15.17 \\
Male (\%) & Mean (\$) & $87,950.56$ & $29,826.01$ & $32,156.18$ & $138,437.69$ \\
& Std. Dev. (\$) & $134,177.31$ & $15,922.53$ & $26,884.04$ & $182,653.20$ \\
& & 54.15 & 56.94 & 55.31 & 49.48 \\
\hline
\end{tabular}




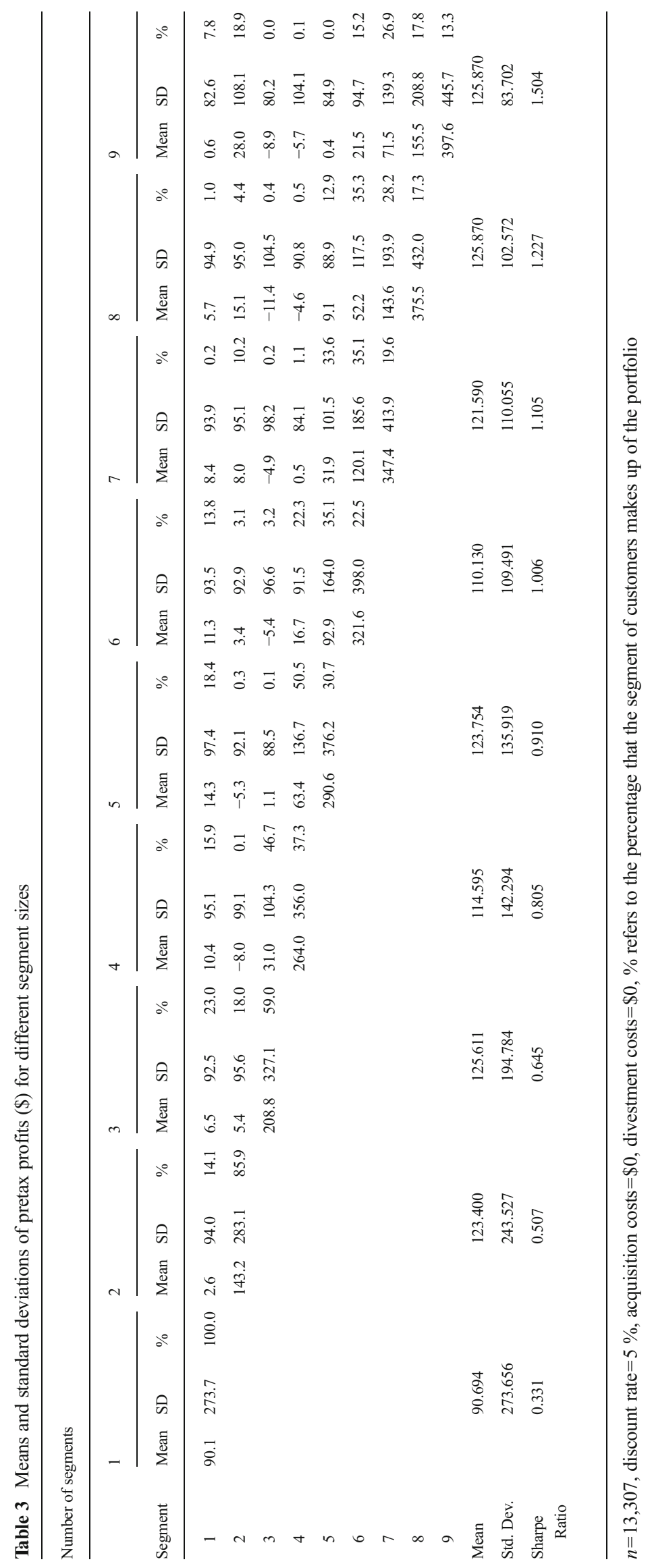



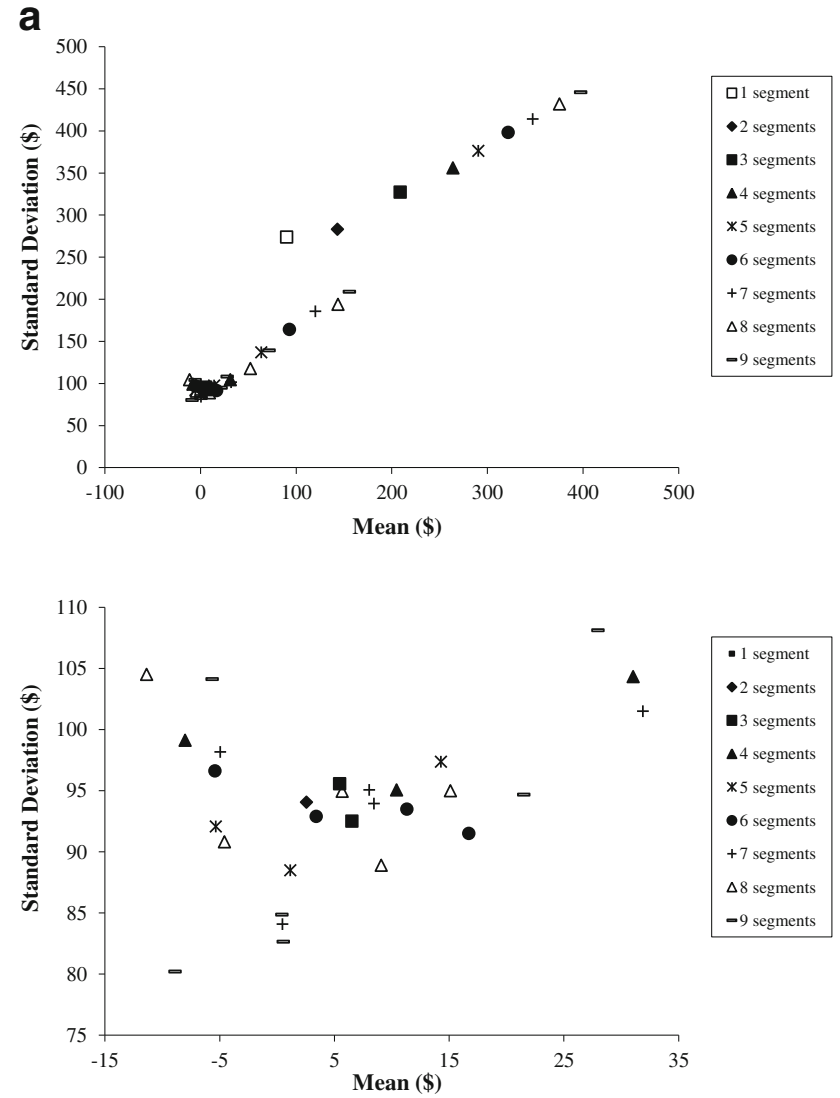

b

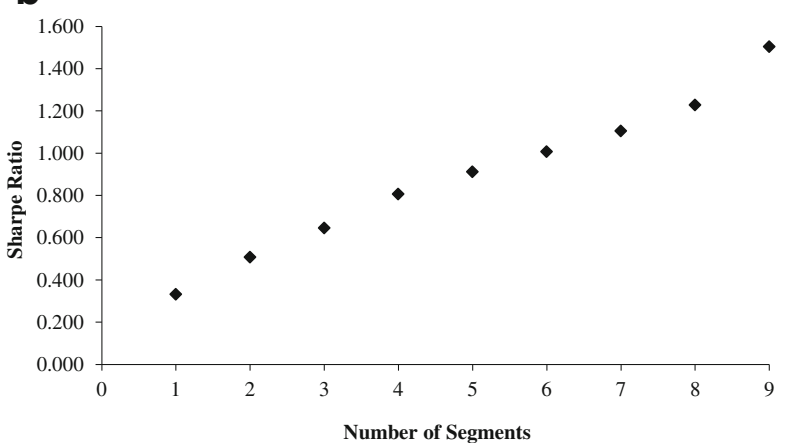

Fig. 2 a. Risk vs return. b: Sharpe ratio per number of segments. Note 1 Nine different segmenting portfolios are shown in Fig. 2a(1) and Fig. $2 \mathrm{a}(2)$ : that is, a one-segment portfolio is shown, a two-segment portfolio is shown,..., a nine-segment portfolio is shown. Each segment within a portfolio is plotted. For instance, the " 5 segments" portfolio will have each of the five segments displayed in the figure, represented by an $X$ marker. Many of the plotted points cluster around a mean of $\$ 15$ and standard deviation of $\$ 95$. This rather crowded area of Fig. 2a(1) is expanded in Fig. 2a(2) for clarity. Note 2 The data for Fig. 2a(1) and Fig. $2 \mathbf{a}(2)$ are taken from Table 3

left of Fig. 2a(1). These five $\Delta \mathrm{s}$ can be seen in Fig. 2a(2), which magnifies the overlapping cluster in Fig. 2a(1).

The results, shown in Fig. 2b, illustrate that as the number of segments increases from one to nine, the Sharpe ratio (calculated by assuming $R_{B}=0$ ) monotonically increases (from 0.331 to 1.504 ). A greater number of segments allow a wider dispersion in mean/standard deviation pairs, and hence a higher Sharpe ratio, but it may also imply higher operational costs. We conclude our analysis at nine segments because insight from managers reveals the impracticality of managing a large number of segments, but the quasi-linear trend of results may still hold with increased segmentation.

Figure 3a disaggregates the Sharpe ratio into risk and return components. The general trend is that the overall portfolio risk decreases and returns increase as the number of customer segments increases.

Profit Measure The bank defines pre-tax profit as the revenue for each customer minus the fixed and variable costs for that customer and we use this as the measure of profit.

Risk/Return Trade-Off Measure Once the segmentation method, number of segments, profit measure, and the measure for an optimal portfolio are determined, a firm then can calculate the optimal allocation of customer segments using the Sharpe ratio. For example, assume that the bank currently manages three segments with an equal number of customers in each, with marketing resources allocated for customer acquisition. Table 3 provides an example for three customer segments of the bank with equal customers in each and shows the ideal segment allocation as $23.0 \%$ (segment 1), $18.0 \%$ (segment 2 ), and $59.0 \%$ (segment 3 ). Therefore, the managers at the

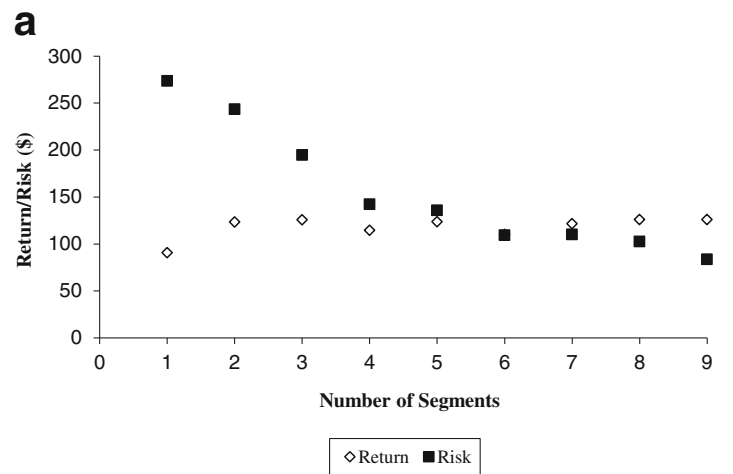

\section{b}

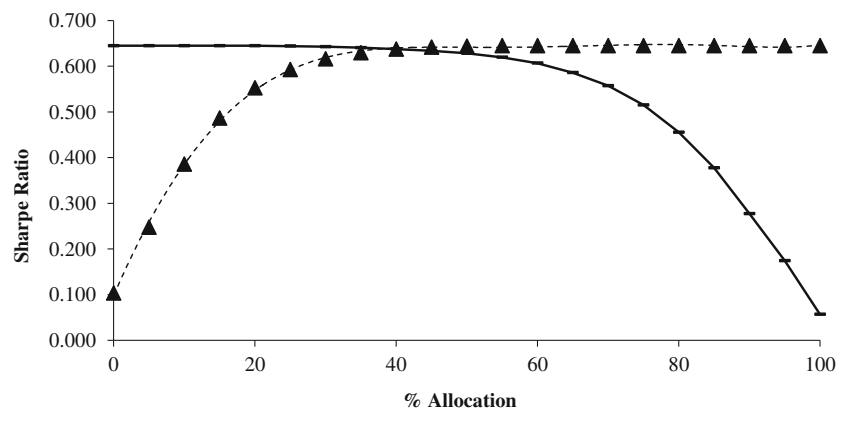

\ Maximum Allocation \% for Segment 3 - Minimum Allocation \% for Segment 2

Fig. 3 a Risk and return for different number of segments. b Comparison of allocation of customers 
bank should allocate their marketing resources toward increasing the number of customers in segment 3 from $33 \%$ to $59 \%$, and/or reducing the number of customers in segment 1 to $23 \%$ and segment 2 to $18 \%$. A number of strategic or financial, such as acquisition, divestment, and retention costs factors may affect whether the ideal segmentation strategy should be implemented.

Minimum/Maximum Percentage of Each Group Our methodology can take into account user specifications constraining the minimum and maximum percentage of a particular segment (see Eq. 8). Figure $3 \mathrm{~b}$ illustrates the results by placing varying minimum constraints on segment 2 in a three segment customer portfolio. We focus on segment 2 because in the initial segmentation it had the lowest allocated percentage of customers, resulting in a substantial change in the Sharpe ratio. The Sharpe ratio holds fairly constant well past the initial allocation for segment 2 (18\%). It is not until approximately $60 \%$ allocation that the Sharpe ratio shows a rapid non-linear decline.

Figure $3 \mathrm{~b}$ also shows the results of varying allocations to segment 3. This segment was selected because it had the highest percentage of customers allocated (when there were no restrictions on the portfolio allocation). Therefore, the overall portfolio should show the largest change as this segment has a cap placed on it. Indeed, as soon as the maximum number of customers in segment 3 drops below $\sim 35 \%$, the Sharpe ratio rapidly declines. Overall, these examples show that there is a lot of leeway in segment allocation as long as a decrease of approximately 0.006 in the optimal the Sharpe ratio is acceptable, which minimizes managerial concerns for having to rebalance the customer portfolio. However, there is a tipping point where the Sharpe ratio will rapidly decline, that should be monitored closely.

Acquisition Costs Acquisition costs add another dimension of complexity to customer portfolios. Assume that the ideal portfolio allocation is $23 \%, 18 \%$, and $59 \%$ for segments 1 , 2 , and 3 respectively, and that the acquisition costs for all three segments is $\$ 0$. If acquisition cost remained at $\$ 0$ then the manager would aim to acquire customers such that the ratio stayed at 23-18-59. However, if the costs for acquiring segment 3 type customers rose to $\$ 70$ per customer, then the manager should reduce the percentage of customers in segment 3.

Of course, acquisition costs can differ for each customer segment. Figure 4 models the costs for segment 3 . The figure shows that the percentage of customers allocated to segment 3 decreases in a non-linear fashion as the acquisition cost rises from $\$ 0$ to $\$ 50$. At the $\$ 50$ level of acquisition cost, the benefits of having additional customers in segments 1 and 2 are the same as acquiring customers for segment 3 . Thus, the percentage of customers in Segment 3 stays at the original allocation of $33 \%$.
Divestment Costs Divestment costs can include closing of customer accounts or sales, general, and administrative (SGA) costs associated with changing the firm's focus from one customer segment to another customer segment. These costs can differ for each customer segment. Figure 5 illustrates possible outcomes by varying the costs of divestment, first for segment 2 and then continuing with segment 1 . We start with segment 2 because it has the lowest initial percentage of customers allocated. Scenarios 1-3 show how increasing the divestment cost of segment 2 makes it more costly to remove these customers than to keep them. This point occurs as soon as their divestment cost reaches $\$ 10$. At this point, segment 2 is at $33 \%$, but segment 1 is under $33 \%$. Scenario 5 shows the increasing costs of divesting for segment 1 . The optimal allocation of each segment is $33.33 \%$ when the cost of divesting segments 1 and 2 are $\$ 10$ per customer.

While the firm management must make decisions to create and optimize its customer portfolio, our methodology shows a path to a greater Sharpe ratio. A naïve model that initially divides customers into three equal sized segments has a Sharpe ratio of $0.560(76.29 / 136.15)$. If the firm is able to acquire and remove customers so the resulting portfolio matches a 23/18/59 split, then Sharpe ratio improves to 0.645 (125.61/194.78). Of course, customers are fluid assets, but fortunately, firms do not need to be exact in the size of each customer segment. For our dataset, there is a minimum of $10 \%$ leeway before a managerially significant change takes place in the Sharpe ratio.

\section{Discussion, Limitations, and Future Research}

We started with the premise that customers are an asset to the company (Table 1) whose risk and return should be considered in developing an optimal customer portfolio. We provide a step-by-step methodology that considers customer acquisition and divestment costs, segment risk and return levels, while taking into account the number of manageable segments, segment size, segmentation method, and the overall risk/reward level for the customer portfolio.

The improvements from evaluating customer segment risk/reward ratios are confirmed by our empirical analysis. A firm can calculate its current risk-reward position and compare it to its desired level. If the firm wishes to adjust its current position, it can acquire or divest customers in specific segments to achieve the desired customer portfolio. Furthermore, firms often have the opportunity to acquire other firms and their customer portfolios. Our methodology allows firms to determine whether the acquisition will produce a more or less desirable customer portfolio. Firms also may use the risk-reward calculations to arrive at a price for customers in a takeover bid. It should be noted that acquiring or divesting specific types of customers is rarely a 
Fig. 4 Comparison of varying acquisition costs of customers for segment 3 from a three-segment portfolio

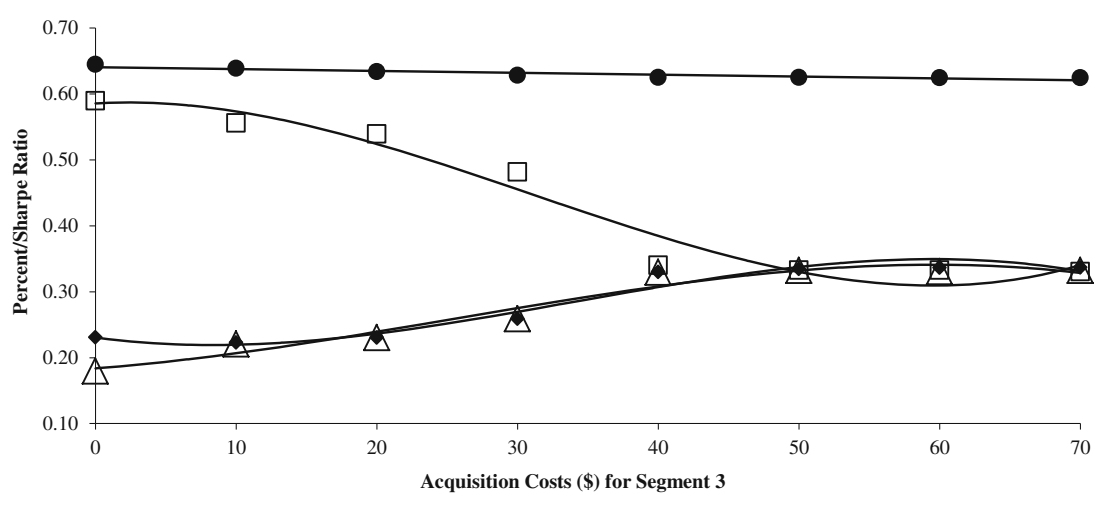

- Sharpe Ratio $\quad \square \%$ from Segment $3 \quad \Delta \%$ from Segment $2 \quad \bullet \%$ from Segment 1 straightforward task. Marketing efforts designed to attract specific customer types may not have their desired effect and it is often difficult to determine, a priori, reasonable parameters of the level and variance of cash flows from these customers.

An advantage of our methodology is that it is straightforward and can be easily implemented with software packages such as Microsoft Excel. In addition, the results are easier to interpret compared with more complex models of portfolio selection. Simplicity and ease of interpretation are important from the perspective of practitioners, but we acknowledge that practitioners might prefer portfolio models other than the mean-variance portfolio model in certain cases. For example, the Markowitz model may be sensitive to high error levels, as with obtaining and estimating data due to uncertainty. Existing methods to correct for these issues include constraining the portfolio weights similar to our methodology [50, 51], using Bayesian estimation for means and covariances [52], or using simulated sampling for estimating the mean and covariance matrix [53]. Bayesian approaches may also be appropriate when a firm is making estimations from limited data.

An issue we did not address directly is managing the dynamics of a customer portfolio. In our study the firm has a pre-specified customer segmentation method. However, other types of firms may have dynamic segmentation methods. The issues of customer retention or reassignment to a new segment are tangential to our methodology [e.g., 54]. Managers also may apply customer movement predictions toward determining the necessary resources in achieving the optimal weights for each customer segment. Instead of acquiring or divesting customers from particular segments, some companies may opt to try to shift the risk and reward profile of a number of their customers thereby changing the overall profile of the customer portfolio. When we created our dataset we removed customers that were not part of the firm for all 7 quarters. We assumed that non-retained customers were randomly distributed across all of the segments. Yet, it is possible that these short-term customers may be more concentrated, as a percentage, in one
Fig. 5 Comparison of divestment costs for segment 1 and 2 from a three-segment portfolio. Note: Scenario 1 Divestment costs for segment $1=\$ 0$; divestment costs for segment $2=\$ 0$. Scenario 2 Divestment costs for segment $1=$ $\$ 0$, divestment costs for segment $2=\$ 5$. Scenario 3 Divestment costs for segment $1=\$ 0$, divestment costs for segment $2=$ $\$ 10$. Scenario 4 Divestment costs for segment $1=\$ 5$, divestment costs for segment $2=\$ 10$. Scenario 5 divestment costs for segment $1=\$ 10$, divestment costs for segment $2=\$ 10$

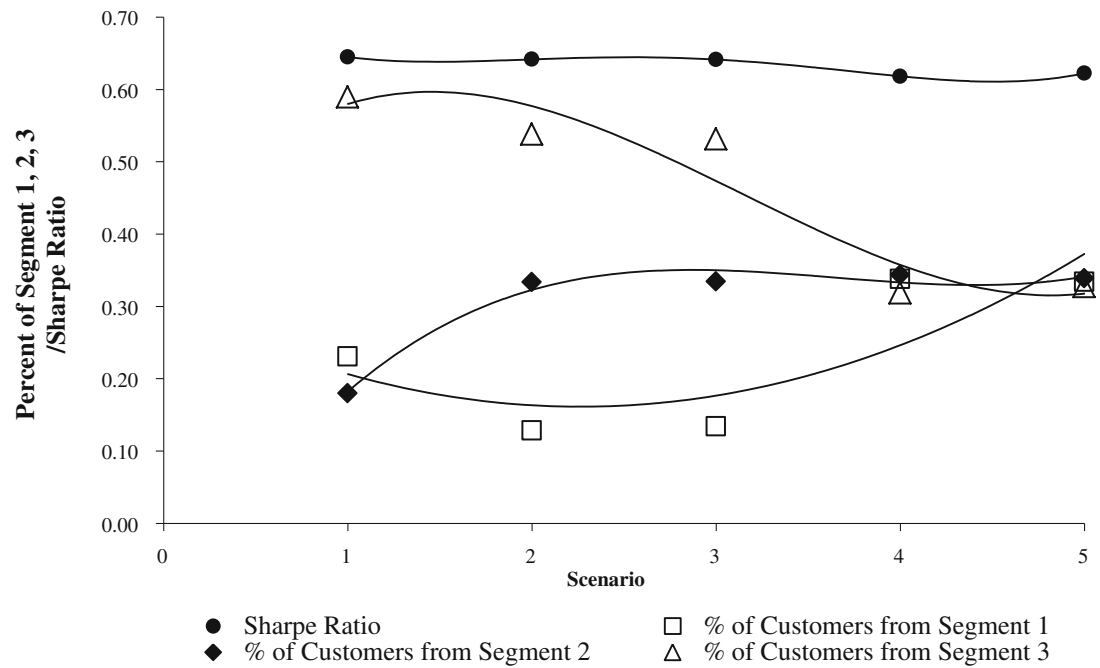


segment compared to another segment. Again, as a further model refinement, such issues could be incorporated.

The segmentation method used in our example was predicated on consumption habits (i.e. embeddedness). Yet, step 2 in Fig. 1 may alert a firm that its current segmentation method may produce segments that are similar in their risk-return profiles. What if a firm uses a segmentation method that is based on psychographic or geographic properties? Segments constructed by geography can have varying consumption habits (e.g., regional unemployment, housing prices, and seasonal items). In a similar manner, psychographic segments may produce varying consumption habits.

Because we take a profit-maximizing firm's perspective, the social welfare implications of portfolio optimization are not fully considered. For instance, certain customer segments may not be served because certain industries such as banks or grocery stores may not have locations in specific environments. Similarly, monetary variables for risk and returns do not take into account other possible firm utility measures such as long-term customer relationship development or maintaining customers with specific characteristics such as high levels of satisfaction. These issues could be incorporated in future models.

In conclusion, we illustrate the importance of monitoring a firm's entire customer portfolio by paying attention to risk as well as return. Firms should concentrate more on collecting the types of customers that enhance their overall return and reduce risk, rather than solely acquiring customers to achieve a size goal, such as becoming the largest banking firm. Customer portfolio risk management can join forms of strategic risk management already employed by firms [55]. Indeed, concern with risk at individual financial institutions has compelled the federal government to take legislative action [56].

Acknowledgments We are grateful to Vithala R. Rao for his guidance and advice throughout the preparation of this manuscript, and indebted to the editor and the two anonymous reviewers for their valuable input which resulted in a much better version of the manuscript. Many thanks to R. Venkatesh, Nivriti Chowdry, Patricia Jaconetta Groening, Kyuhong Han, and Yang Wang for their help in preparation of this publication.

\section{References}

1. Morningstar (2008) Goldman Sachs: bank holding status won't change strategy. http://news.morningstar.com/newsnet/ViewNews. aspx?article=/DJ/200811111654DOWJONESDJONLINE000531_ univ.xml. Accessed 12/06/2008

2. Srivastava RK, Shervani T, Fahey L (1998) Market-based assets and shareholder value: a framework for analysis. J Mark Res 62(1):2-18

3. Gupta S, Lehmann DR, Stuart JA (2004) Valuing customers. J Mark Res 41(1):7-18

4. Trautwein F (1990) Merger motives and merger prescriptions. Strateg Manag J 11(4):283-295

5. Bettis RA, Mahajan V (1985) Risk/return performance of diversified firms. Manag Sci 31(7):785-799
6. Bettis RA (1983) Modern financial theory, corporate strategy and public policy: three conundrums. Acad Manag Rev 8(3):406-415

7. Nenonen S (2008) Why finance does not help customer asset management - challenges in applying financial theories to customer relationship management. Paper presented at the Academy of Marketing Science Annual Conference 2008

8. Caldieraro F, Coughlan AT (2009) Optimal sales force diversification and group incentive payments. Mark Sci 28(6):1009-1026

9. Dhar R, Glazer R (2003) Hedging customers. Harv Bus Rev 81(5): $86-92$

10. Tarasi CO, Bolton RN, Hutt MD, Walker BA (2011) Balancing risk and return in a customer portfolio. J Mark 75(3):1-17

11. Wubben M, Wangenheim FV (2008) Instant customer base analysis: managerial heuristics often "get it right". J Mark 72(3):82-93

12. Xia J, Yan J-A (2006) Markowitz's portfolio optimization in an incomplete market. Math Financ 16(1):203-216

13. Ball R, Brown P (1969) Portfolio theory and accounting. J Account Res 7(2):300-323

14. Ryals L (2003) Making customers pay: measuring and managing customer risk and returns. J Strateg Mark 2:165-175

15. Buhl HU, Heinrich B (2008) Valuing customer portfolios under riskreturn-aspects: a model-based approach and its application in the financial services industry. Acad Mark Sci Rev 12(5):1-32

16. Zhao Y, Zhao Y, Song I (2009) Predicting new customers' risk type in the credit card market. J Mark Res 46(4):506-517

17. Elton EJ, Gruber MJ (1997) Modern portfolio theory, 1950 to date. J Bank Financ 21(11-12):1743-1759

18. Hlavacek JD, Ames BC (1986) Segmenting industrial and high-tech markets. J Bus Strateg 7(2):39-50

19. Wedel M, Kamakura WA (2003) Market segmentation: conceptual and methodological foundations, 3rd edn. Kluwer Academic Publishers, Norwell

20. Moorthy KS (1984) Market segmentation, self-selection, and product line design. Mark Sci 2(4):288-307

21. Smith WR (1956) Product differentiation and market segmentation as alternative marketing strategies. J Mark 21(1):3-8

22. Emmelhainz MA, Kavan CB (1999) Using information as a basis for segmentation and relationship marketing: a longitudinal case study of a leading financial services firm. J Mark-Focus Manag 4(2):161-177

23. Kamakura WA, Russell GJ (1989) A probabilistic choice model for market segmentation and elasticity structure. J Mark Res 26(4):379-390

24. KeyCorp Community Banking KeyCorp Community Banking Presentations (2006) In: Mooney BE (ed) BancAnalysts Association Boston Conference

25. Lee JH, Park SC (2005) Intelligent profitable customers segmentation system based on business intelligence tools. Expert Syst Appl 29(1):145-152

26. Wangenheim FV, Lentz P (2005) Understanding your customer portfolio: a simple approach to customer segmentation to lifecycle dynamics. Available at SSRN: http://ssrn.com/abstract=782064

27. Venkatesan R, Kumar V (2004) A customer lifetime value framework for customer selection and resource allocation strategy. J Mark 68(4): $106-125$

28. Machauer A, Morgner S (2001) Segmentation of bank customers by expected benefits and attitudes. Int J Bank Mark 19(1):6-17

29. Hwang H, Jung T, Suh E (2004) An LTV model and customer segmentation based on customer value: a case study on the wireless telecommunication industry. Expert Syst Appl 26(2):181-188

30. Reinartz WJ, Thomas JS, Kumar V (2005) Balancing acquisition and retention resources to maximize customer profitability. J Mark 69(1): 63-79

31. Ryals L (2005) Making customer relationship management work: the measurement and profitable management of customer relationships. J Mark 69(4):252-261

32. Krapfel RKJ, Salmond D, Spekman R (1991) A strategic approach to managing buyer-seller relationships. Eur J Mark 25(9):22-37 
33. Haspeslagh P (1982) Portfolio planning: uses and limits. Harv Bus Rev 60(1):58-73

34. Day GS (1977) Diagnosing the product portfolio. J Mark 41(2):29-38

35. Cardozo RN, Smith DK Jr (1983) Applying financial portfolio theory to product portfolio decisions: an empirical study. J Mark 47(2):110-119

36. Cardozo RN, Wind J (1985) Risk return approach to product portfolio strategy. Long Range Plan 18(2):77-85

37. Johnson MD, Selnes F (2004) Customer portfolio management: toward a dynamic theory of exchange relationships. J Mark 68(2): $1-17$

38. Yorke DA, Droussiotis G (1994) The use of customer portfolio theory: an empirical study. J Bus Ind Mark 9(3):6-18

39. Chen P-Y, Hitt LM (2002) Measuring switching costs and their determinants in internet enabled businesses: a study of the online brokerage industry. Inf Syst Res 13(3):255-276

40. Haenlein M, Kaplan AM, Schoder D (2006) Valuing the real option of abandoning unprofitable customers when calculating customer lifetime value. J Mark 70(3):5-20

41. Mittal V, Sarkees M, Murshed F (2008) The right way to manage unprofitable customers. Harv Bus Rev 86(4):94-102

42. Sharpe WF (1994) The Sharpe ratio. J Portf Manag 21(1):49-58

43. Konno H, Yamazaki H (1991) Mean-absolute deviation portfolio optimization model and its applications to Tokyo Stock Market. Manag Sci 37(5):519-531

44. Treynor JL, Black F (1973) How to use security analysis to improve portfolio selection. J Bus 46(1):66-86
45. Choi YK, Murthi BPS (2001) Relative performance evaluation of mutual funds: a non-parametric approach. J Bus Finance Account 28(7/8):853-876

46. Markowitz HM (1952) Portfolio selection. J Financ 7(1):77-91

47. Queen LE (2006) The Laws of customer attraction. Bank Strateg 72(3):82-93

48. Rylander D, Strutton D, Pelton LE (1997) Toward a synthesized framework of relational commitment: implications for marketing channel theory and practice. J Mark Theory Pract 5(2):58-71

49. Kumar V, Venkatesan R (2005) Who are the multichannel shoppers and how do they perform?: correlates of multichannel shopping behavior. J Interact Mark 19(2):44-62

50. Chopra VK (1993) Improving optimization. J Invest 8:51-59

51. Frost PA, Savarino JE (1986) An empirical Bayes approach to efficient portfolio selection. J Financ Quant Anal 21(3):293-305

52. Black F, Litterman R (1990) Asset allocation: combining investor views with market equilibrium. Fixed Income Research, New York

53. Michaud RO (1998) Efficient asset management: a practical guide to stock portfolio optimization and asset allocation, 2nd edn. Harvard Business School Press, Boston

54. Homburg C, Steiner VV, Totzek D (2009) Managing dynamics in a customer portfolio. J Mark 73(5):70-89

55. Baird IS, Thomas H (1985) Toward a contingency model of strategic risk taking. Acad Manag Rev 10(2):230-243

56. BusinessWeek (2009) Financial regulations: what Obama wants. Theo Francis and Jane Sasseen 